OPEN ACCESS

Edited by:

Yan Li,

Nanjing University, China

Reviewed by:

Larisa Y. Poluektova

University of Nebraska Medical Center, United States

Masakazu Kamata

University of Alabama at Birmingham, United States

Ramesh Akkina,

Colorado State University, United States

*Correspondence: Amy Gillgrass

gillgra@mcmaster.ca

Specialty section: This article was submitted to Viral Immunology, a section of the journal

Frontiers in Immunology

Received: 14 October 2020 Accepted: 30 December 2020

Published: 05 March 2021

Citation:

Gillgrass A, Wessels JM, Yang JX and Kaushic $C$ (2021) Advances in Humanized Mouse Models to Improve Understanding of HIV-1 Pathogenesis and Immune Responses.

Front. Immunol. 11:617516. doi: 10.3389/fimmu.2020.617516

\section{Advances in Humanized Mouse Models to Improve Understanding of HIV-1 Pathogenesis and Immune Responses}

\author{
Amy Gillgrass ${ }^{1,2,3 *}$, Jocelyn M. Wessels ${ }^{4}$, Jack X. Yang ${ }^{1,2,3}$ and Charu Kaushic ${ }^{1,2,3}$ \\ ${ }^{1}$ Department of Medicine, McMaster University, Hamilton, ON, Canada, ${ }^{2}$ McMaster Immunology Research Centre, \\ McMaster University, Hamilton, ON, Canada, ${ }^{3}$ Michael G. DeGroote Institute for Infectious Disease Research, McMaster \\ University, Hamilton, ON, Canada, ${ }^{4}$ Department of Obstetrics and Gynecology, McMaster University, Hamilton, ON, Canada
}

Although antiretroviral therapy has transformed human immunodeficiency virus-type 1 $(H I V-1)$ from a deadly infection into a chronic disease, it does not clear the viral reservoir, leaving HIV-1 as an uncurable infection. Currently, 1.2 million new HIV-1 infections occur globally each year, with little decrease over many years. Therefore, additional research is required to advance the current state of HIV management, find potential therapeutic strategies, and further understand the mechanisms of HIV pathogenesis and prevention strategies. Non-human primates (NHP) have been used extensively in HIV research and have provided critical advances within the field, but there are several issues that limit their use. Humanized mouse (Hu-mouse) models, or immunodeficient mice engrafted with human immune cells and/or tissues, provide a cost-effective and practical approach to create models for HIV research. Hu-mice closely parallel multiple aspects of human HIV infection and disease progression. Here, we highlight how innovations in Hu-mouse models have advanced HIV-1 research in the past decade. We discuss the effect of different background strains of mice, of modifications on the reconstitution of the immune cells, and the pros and cons of different human cells and/or tissue engraftment methods, on the ability to examine HIV-1 infection and immune response. Finally, we consider the newest advances in the Hu-mouse models and their potential to advance research in emerging areas of mucosal infections, understand the role of microbiota and the complex issues in HIV-TB co-infection. These innovations in Hu-mouse models hold the potential to significantly enhance mechanistic research to develop novel strategies for HIV prevention and therapeutics.

Keywords: HIV-1, humanized mouse, pathogenesis, immune response, mucosal infection, microbiota, coinfection, vaccines 


\section{INTRODUCTION}

Currently approximately 38 million people are living with human immunodeficiency virus-type 1 (HIV-1), the underlying cause of acquired immune deficiency syndrome (AIDS) (1). Although treatment with antiretroviral therapy (ART) has transformed HIV from a deadly infection into a chronic disease, it does not clear the latent viral reservoir, therefore there is still no cure for HIV infection (2). Furthermore, even with ART, HIV infection increases risks of co-infection with other pathogens such as Mycobacterium tuberculosis $(M t b)$ (3). Additional research is required to advance the current state of HIV management and potential therapeutic strategies, in addition to understanding mechanisms of HIV pathogenesis. Although animal models such as non-human primates (NHP) have been used extensively in HIV research and have provided critical advances in knowledge within the field, there are several issues including host-restriction factors, ethics, and cost that can limit their use $(4,5)$. Furthermore, the human speciesspecific tropism of HIV-1 has prevented the use of traditional murine models leading to a lack of small animal models for in vivo HIV-1 research (6).

Humanized mouse (Hu-mouse) models, or immunodeficient mice engrafted with human immune cells and/or tissues, provide a cost-effective and practical approach to creating models for HIV-1 research. Unlike traditional mouse models, Hu-mouse models effectively sustain HIV-1 infections while also recapitulating relatively accurate in vivo immune responses to the infection due to the reconstitution with human immune cells when compared to other animal models (7). This review will outline the advances in Hu-mouse models that have made them useful in HIV-1 research and a convenient alternate to NHP. Furthermore, numerous novel modifications of $\mathrm{Hu}$-mice demonstrate potential to advance knowledge in virus transmission, infection, evolution, pathogenesis, prevention, latency, cure, and disease interaction such as $M t b$ co-infection. Additionally, since the major physiological route of HIV-1 transmission in humans is by the mucosal route (intrarectally or intravaginally) (8), this review will detail the use of Hu-mice in elucidating mechanisms involving mucosal infections and discuss how microbiota may be involved.

\section{HU-MOUSE MODELS FOR HIV-1 RESEARCH}

Currently, some of the most widely used Hu-mouse models in HIV research take advantage of three major immunocompromised features which allow for the successful engraftment of human cells or tissues. NOD.Cg-Prkdc ${ }^{\text {scid }} \mathrm{Il} 2 \mathrm{rg}^{\text {tm } 1 \text { Sug }}$ (NOG) (9), NOD.Cg-Prkdc ${ }^{\text {scid }} \mathrm{Il} 2 \mathrm{rg}^{\mathrm{tm} 1 \mathrm{Wjl}}$ (NSG) $(10,11)$, and NOD.CgRag1 ${ }^{\text {tm1MoM }}$ Il2rg ${ }^{\text {tm1Wjl }}$ (NRG) (12) are on the non-obese diabetic (NOD) background that leads to suppressed mouse macrophage phagocytic activity. Mice with the Prkdc ${ }^{\text {scid }}$ or Rag1/Rag2 loci mutation lack mature $\mathrm{T}$ and $\mathrm{B}$ lymphocytes while the $I l 2 \mathrm{rg}$ gene mutation effectively eliminates mouse NK cell activity (13). The most common engraftment method of human cells is the intravenous or intrahepatic injection of CD34+ hematopoietic stem cells (14) into adult or newborn immunodeficient mice, respectively, after myeloablative irradiation or administration of myeloablative doses of drugs such as busulfan (15). This engraftment method has been performed in each model (NOG, NSG, NRG) yielding reconstitution of human CD4+ and CD8+ T cells, monocytes, macrophages, dendritic cells (DCs) and progenitor $\mathrm{B}$ cells in peripheral blood, primary and secondary lymphoid tissues $(12,16)$.

The unique engraftment method using surgical implantation of human fetal liver and thymus tissues followed by injection of matched CD34+ hematopoietic stem cells (HSCs) gave rise to the bone marrow liver thymus (BLT) model (17-19). The human thymic tissue allows for T cell education in the context of human cells (20). Both HSC-only and BLT methods are able to successfully reconstitute human monocytes, dendritic cells, $\mathrm{T}$ cells, and B cells in peripheral blood and tissues, but higher cell counts were observed in the BLT engraftment method $(21,22)$. The HSC-only method demonstrated better human B cell and myeloid cell development (21) while additional thymus support yielded higher $\mathrm{CD}^{+} \mathrm{T}$ cell reconstitution in the spleen (21), gastrointestinal (GI) (22) and gut-associated lymphoid (GALT) tissues $(18,21,23)$ (Table 1). Both methods have demonstrated similar susceptibility to HIV infection, trends in CD4+ T cell depletion, and persistent viral reservoirs in vivo (21). The major difference between the two methods is that BLT-engrafted mice have measurable $\mathrm{T}$ cell response against HIV-1 because the human thymic tissue allows the resulting $\mathrm{T}$ cells to respond to the HIV-1 antigen presentation by human leukocyte antigen (HLA) generating HLA-restricted anti-HIV-1 human $\mathrm{T}$ cell response, which is absent in the current HSC-only method (18, 48) (Table 1). This has led to the BLT model being the current gold standard for studying HIV-1 immune responses (17, $49,50)$.

\section{HSC ENGRAFTMENT MODELS (CURRENT GENERATION): NOG, NSG, NRG, DKO/BRG, NSG-BLT}

\section{NOG and NSG}

The NOG and NSG mice differ in the IL-2 receptor gene (Il2rg) which is truncated in NOG and knocked-out in NSG. Both humanized NOG (hu-NOG) and humanized NSG (hu-NSG) mice have demonstrated successful engraftment of HSC with substantial human lymphoid repopulation (29, 51-53). Intraperitoneal and intravenous routes of HIV-1 infection into both types of mice demonstrated viremia and viral dissemination throughout lymphoid tissues (29, 51-54).

$\mathrm{Hu}-\mathrm{NOG}$ mice have furthered the understanding of HIV-1 transmission as well as treatment testing and development. These mice can generate B cells that secrete isotype-switched, HIV-specific IgG antibodies (16). Studies using hu-NOG models investigated the role of human anti-viral factors in human transmission of HIV-1 (55) and treatment options with novel therapeutics such as zinc-finger nucleases (ZFN) showing reduced viral loads and increased CD4+ T cell counts (56). Additionally, viral evolution and replication kinetics have been 
TABLE 1 | Summary of reported reconstitution of major human immune cell types within current generation and next generation hu-mice for HIV studies.

\begin{tabular}{|c|c|c|}
\hline Humanized Mouse Model & Human immune cell reconstitution & References \\
\hline \multicolumn{3}{|l|}{ Current Generation Models } \\
\hline HSC-DKO/BRG & $\begin{array}{l}\text { PB: CD45+ lymphocytes, CD4+ T cells, CD8+ T cells } \\
\text { BM: CD45+ lymphocytes, mature and immature B cells } \\
\text { LT: CD45+ lymphocytes, CD3+ T cells, CD4+ T cells, CD8+ T cells, T regulatory cells, mature and immature B cells }\end{array}$ & $(24-27)$ \\
\hline HSC-NOG & $\begin{array}{l}\text { PB: CD45+ lymphocytes, CD3+ T cells, immature B cells } \\
\text { BM: CD45+ lymphocytes, immature B cells } \\
\text { LT: CD45+ lymphocytes, CD4+ T cells, CD8+ T cells, immature B cells }\end{array}$ & $(16,28)$ \\
\hline $\begin{array}{l}\text { HSC-NSG } \\
\text { HSC-NRG }\end{array}$ & $\begin{array}{l}\text { PB: CD3+ T cells, immature B cells } \\
\text { BM: CD45+ lymphocytes, mature and immature B cells, immature NK cells } \\
\text { LT: CD4+ T cells, CD8+ T cells, mature and immature B cells } \\
\text { FRT: CD45+ cells, CD4+ T cells, CD68+ macrophages }\end{array}$ & $(12,29-31)$ \\
\hline NSG-BLT ${ }^{\star}$ & $\begin{array}{l}\text { PB: CD3+ T cells, CD4+ T cells, CD8+ T cells, immature B cells } \\
\text { BM: CD45+ lymphocytes, mature and immature B cells } \\
\text { LT: CD4+ T cells, CD8+ T cells, mature and immature B cells } \\
\text { GI: CD45+ lymphocytes, CD4+ T cells, CD8+ T cells, B cells, CD68+ macrophages, dendritic cells } \\
\text { FRT: CD3+ T cells, CD4+ T cells, CD68+ macrophages, CD11c+ dendritic cells }\end{array}$ & $(18,32,33)$ \\
\hline \multicolumn{3}{|l|}{ Next Generation Models } \\
\hline $\begin{array}{l}\text { HSC-DRAG* } \\
\text { HSC-DRAGA* }\end{array}$ & $\begin{array}{l}\text { PB: CD3+ T cells, CD4+ T cells, CD8+ T cells, isotype switched mature B cells } \\
\text { BM: CD45+ lymphocytes } \\
\text { LT: CD45+ lymphocytes, CD4+ T cells, CD8+ T cells, T regulatory cells, dendritic cells } \\
\text { GI: CD45+ lymphocytes, CD4+ T cells, CD8+ T cells, naïve and memory B cells } \\
\text { FRT: CD4+ T cells, T follicular helper cells, naïve and memory B cells }\end{array}$ & $(34-36)$ \\
\hline $\begin{array}{l}\text { HSC-BRGST } \\
\text { HSC-BRGSA2DR2* }\end{array}$ & $\begin{array}{l}\text { PB: CD45+ lymphocytes, CD3+ T cells, CD4+ T cells, CD8+ T cells, T follicular helper cells (HSC-BRGST only), } \\
\text { isotype switched mature B cells } \\
\text { BM: CD45+ lymphocytes, isotype switched B cells } \\
\text { LT: CD45+ lymphocytes, CD4+ T cells, CD8+ T cells, isotype switched mature B cells, T follicular helper cells (HSC- } \\
\text { BRGST only), central and effector memory T cells }\end{array}$ & $(37,38)$ \\
\hline NSGW-NeoThy & $\begin{array}{l}\text { PB: CD45+ lymphocytes, CD3+ T cells, CD4+ T cells, CD8+ T cells, regulatory T cells, B cells, monocytes/ } \\
\text { macrophages } \\
\text { BM: CD45+ lymphocytes, CD3+ T cells, B cells } \\
\text { LT: CD45+ lymphocytes, CD3+ T cells, regulatory T cells, B cells, monocytes/macrophages }\end{array}$ & (39) \\
\hline HSC-NOG-EXL & $\begin{array}{l}\text { PB: CD4+ T cells, CD8+ T cells, CD33+ myeloid cells, basophils, neutrophils, NK cells, monocytes, dendritic cells } \\
\text { BM: CD3+ T cells, B cells, mast cells, basophils } \\
\text { LT: CD3+ T cells, B cells, mast cells, basophils, dendritic cells } \\
\text { GI: Mast cells, basophils }\end{array}$ & $(40,41)$ \\
\hline HSC-NSGS/NSG-SGM3 & $\begin{array}{l}\text { PB: CD4+ T cells, B cells, T regulatory cells } \\
\text { BM: CD3+ T cells, CD4+ T cells, T regulatory cells, B cells, dendritic cells } \\
\text { LT: CD3+ T cells, CD4+ T cells, T regulatory cells, B cells, CD33+ myeloid cells }\end{array}$ & $(42-44)$ \\
\hline HSC-SRG-15 & $\begin{array}{l}\text { PB: CD45+ lymphocytes, mature NK cells } \\
\text { BM: mature NK cells, CD45+ lymphocytes, CD3+ T cells, CD4+ T cells, CD8+ T cells } \\
\text { LT: tissue-resident NK cells, CD45+ lymphocytes, CD3+ T cells, CD4+ T cells, CD8+ T cells }\end{array}$ & (31) \\
\hline HSC-NSG-15 & $\begin{array}{l}\text { PB: mature NK cells, CD3+ T cells } \\
\text { BM: mature NK cells, CD45+ lymphocytes, CD3+ T cells, CD4+ T cells, CD8+ T cells, B cells } \\
\text { LT: mature NK cells, CD45+ lymphocytes, CD3+ T cells, CD4+ T cells, CD8+ T cells, B cells }\end{array}$ & $(45)$ \\
\hline $\begin{array}{l}\text { HSC-MITRG } \\
\text { HSC-MISTRG }\end{array}$ & $\begin{array}{l}\text { PB: Monocytes, functional NK cells, CD45+ lymphocytes, CD3+ T cells, naïve CD4+ T cell, naïve CD8+ T cell, } \\
\text { immature B cells } \\
\text { BM: CD45+ lymphocytes, CD33+ myeloid cells, functional monocytes } \\
\text { LT: functional NK cells, monocytes, dendritic cells } \\
\text { Gl: CD68+ myeloid cells }\end{array}$ & $(46,47)$ \\
\hline
\end{tabular}

PB, Peripheral blood; BM, Bone marrow; LT, Primary and secondary lymphoid tissue; Gl, Gastrointestinal organs; FRT, Female reproductive tract. ${ }^{*} H L A$-restricted immune responses observed.

investigated using this model using various HIV-1 strains (57). Finally, hu-NOG mice were also used to investigate the efficacy of ART, long-acting antiretroviral compounds that showed reduced viral load and recovery of $\mathrm{CD} 4+\mathrm{T}$ cell counts, and a latent viral reservoir with $\mathrm{T}$ cell depletion after treatment was stopped, similar to that seen in humans (58).

Numerous HIV-1 treatment methods have been tested on huNSG mice including combination ART (cART) $(29,59)$, highly 
active antiretroviral therapy (HAART), and neutralizing antibody treatment (54). Similar to the response seen in huNOG mice, latent infection was established and persisted during treatment $(29,59)$. Resting memory CD4+ T cells were the major viral reservoir (29), unaffected by the length of cART treatment (59). A recent study using hu-NSG mice showed that HIV-1 hematopoietic stem/progenitor cell-based gene therapy targeting CCR5 and HIV-1 LTR could be used as anti-HIV strategy (60). Another study tested long-acting, slow-release antiviral therapy in combination with CRISPR-Cas9 gene editing to eliminate latent HIV-1 in Hu-mice, and was the first to demonstrate that permanent viral elimination is possible (61). Additionally, the hu-NSG model has been used to provide better understanding of HIV-1 pathogenesis. The model revealed that cell-to-cell viral transmission efficiently disseminated infection within tissues, suggesting anatomically localized spread would be an area of future investigation for targeted treatments (62). HIV-1 disease progression was also investigated in hu-NSG mice by tracking viral seeding into different tissue compartments providing a picture of the HIV-1 infection timeline (63). Although it has been demonstrated that hu-NSG mice successfully reconstitute human CCR5+ CD4+ $\mathrm{T}$ cells within the female reproductive tract (FRT) $(29,30)$, to date, HSC-engrafted NSG mice have not been utilized widely to study mucosal and sexual transmission of HIV-1 (30).

\section{NRG and DKO (BRG)}

Like the NSG model, the more radioresistant hu-NRG have similar successful engraftment of human peripheral blood mononuclear cells (PBMCs) or HSCs (12). HSC-engrafted NRG mice demonstrated successful mucosal HIV-1 challenge with viral dissemination throughout the FRT and lymphoid tissues $(64,65)$. An older, yet similar model without the NOD background termed Rag1 ${ }^{\text {null }} \mathrm{Il} 2 \mathrm{rg}^{\text {null }}$ or Rag2 ${ }^{\text {null }} \mathrm{Il} 2 \mathrm{rg}^{\text {null }}$ (DKO) mice (also known as BRG mice) $(11,66)$, also demonstrated susceptibility to both R5- and X4-tropic variants of HIV-1 via vaginal and rectal mucosal transmission with insights on therapy efficacy, latency and chronic infection (24-26, 67, 68). Furthermore, hu-DKO/hu-BRG mice have greatly contributed to cross-species transmission and viral evolution investigations $(69,70)$, as well as the development of $\mathrm{Hu}$-mice based viral outgrowth assays to further the understanding of HIV latency $(71,72)$. Successful mucosal infection in hu-DKO and hu-NRG mice best models natural human routes of HIV-1 transmission and allows studies of microbiota alteration (65) and topical preexposure prophylaxis (PrEP) $(67,73-76)$.

Studies using hu-NRG mice investigated the role of plasmacytoid dendritic cells during infection (77) and HIV-1 latency, and revealed the persistence of type 1 interferon (IFN) signaling after cART treatment (78). Furthermore, therapeutics that enhance ART treatment such as broadly neutralizing antibodies (79) showed promise in this model for prevention of cell-to-cell HIV-1 transmission $(80,81)$. Novel CRISPR/CAS9 genome editing technology was used in PBMC-engrafted NRG mice and demonstrated excision of HIV-1 pro-viral DNA which reduced levels of HIV-1 (82). Additionally, single-cell RNAsequencing was used in this model to characterize human innate immune cells in lymphoid tissues (83). Interestingly, despite the lack of isotype-switched mature B cells, hu-NRGs can still be a useful tool for certain vaccine investigations (84).

\section{NSG-BLT Engraftment Model}

Compared to HSC-engrafted DKO, NSG, and NRG, the BLT engrafted NSG (NSG-BLT) hu-mice have the best overall reconstitution and functional human immune system for studying immune responses to HIV-1 infection (18, 49, 85, $86)$. For this reason, the BLT mice are currently considered the gold standard for HIV-1 research in murine models $(17,49,50)$. BLT mice have been shown repeatedly to sustain mucosal HIV-1 infection and CD4+ T cell reconstitution in the FRT $(32,87)$.

The NSG-BLT mice have been frequently used for testing HIV-1 prevention and therapy. Studies examining therapeutics such as the long-acting ART raltegravir (88), ultra-long-acting antiretroviral dolutegravir (89), and PreP therapies such as the nucleoside reverse transcriptase inhibitor (NRTI) 4'-ethynyl-2fluoro-2'-deoxyadenosine (EFdA) take advantage of the reconstituted human immune cell population in the mucosa (90). These studies have demonstrated effective inhibition of HIV-1 replication, reduction of $\mathrm{HIV}-1$ viral load, and protection from multiple high-dose HIV-1 challenges $(87,88,89,90)$. Other studies using the NSG-BLT model provided valuable insights into HIV-1 treatment, viral evolution, prevention strategies, dose testing, tissue concentration, and pharmacokinetic data $(74,91-$ 95). NSG-BLT Hu-mice have also been used to investigate potential treatment methods including anti-human IFN receptor 2 (IFNR2) (96) and anti-IFN- $\alpha / \beta$ receptor (IFNAR) antibodies (78) in conjunction with ARTs to successfully diminish viral reservoir size in lymphoid tissue and delay viral rebound $(78,96)$. A novel therapeutic strategy using chimeric antigen receptor modified stem cells successfully repopulated NSG-BLT mice with HIV-specific lymphoid populations and demonstrates potential for use in HIV treatment and cure studies (97). The efficacy of both HIV-1 reverse transcriptase inhibitor EFdA (98) and latency-reversing agents such as panobinostat (99) were also studied within the lymphoid compartments to elucidate effects on viral reservoir and latency. Finally, the NSGBLT model is among the Hu-mice that can be used to evaluate the efficacy of potential HIV vaccines as demonstrated through significant $\mathrm{T}$ cell protection upon gag-specific vaccine administration (100). The development of proof of concept vaccines for therapeutic treatment has also been tested in the NSG-BLT model. In a lentiviral-based DC vaccine, HIV-1 antigen (SL9 epitope) is expressed with CD40 ligand to stimulate DC responses and Programmed Death 1 (PD-1) to prevent checkpoint activation (101). This vaccine demonstrated the ability to induce antigen-specific T cells and memory (101). Although unable to induce protection it was able to decrease viral load in the short term (101). In a similar model (NRG with fetal thymus implanted), another therapeutic vaccine expressing 5 CD4 and CD8 HIV specific T cell epitopes with CD40 ligand and administered with TLR3 agonist PolyI:C was successful at inducing anti-HIV CD8 and CD4 $\mathrm{T}$ cell responses, reactivated $\mathrm{HIV}$ reservoirs in cART controlled HIV infected mice, and decreased cell associated viral DNA (102). 
UNDERSTANDING MUCOSAL

\section{TRANSMISSION OF HIV-1 AND THE EFFECT OF MICROBIOTA USING HU-MOUSE MODELS}

It is well recognized that more than $80 \%$ of $\mathrm{HIV}-1$ infections occur through sexual transmission at mucosal surfaces, primarily the lower intestinal tract and female and male genital tract (8). While significant progress has been made in the understanding of mucosal transmission and pathogenic progression of HIV-1 through clinical studies and NHP models, the Hu-mice models present excellent model systems to recapitulate many features of mucosal infection in humans (103-106).

Most Hu-mouse experiments that have focused on mucosal (intrarectal or intravaginal) HIV-1 transmission have assessed prevention of infection using a wide variety of potential prophylactic agents. In these experiments, cell-free (including transmitted/founder strains) and cell-associated HIV-1 were used to challenge Hu-mice via the rectal or vaginal routes $(24,33,64,65$, 94). While most of the mucosal prevention studies focused on the vaginal route of transmission, several have assessed the efficacy of PrEP preventions in Hu-mice challenged intrarectally. Topical microbicides (91), C5A in BLT mice (107), topically delivered ARVs (tenofovir disoproxil fumarate (TDF) and emtricitabine (FTC)) in BLT (108) are some of the prophylactic agents tested. Many studies tested various formulations, routes, pharmacokinetic and challenge routes. Different studies reported complete or partial protection against a single dose intrarectal challenge with HIV-1 (91, 94). Using the DKO model, tissue distribution of the interventions has also been assessed $(73,74)$. In studies focused on the vaginal route of transmission, many studies examined the efficacy of topical microbicides in DKO and BLT models $(75,92$, 108-116). While most studies reported complete protection against single dose intravaginal challenge with HIV-1, others report only partial $(89,110,113-117)$, or no protection (110).

Repeated, and often high dose, intravaginal exposure model has been tested to examine the effectiveness of the prophylactic intervention $(88,89,94,114)$. While it is likely that repeated, low dose viral challenges mimic vaginal transmission of HIV-1 in women more closely than high dose challenges, both experimental designs provide the opportunity to answer different research questions about prophylactic interventions. Interestingly, a few studies found delayed HIV-1 infection and dissemination when vaginal and systemic levels of drug were reduced or after drug cessation $(112,114,115)$. Thus Hu-mice models can be useful in studying imperfect patient adherence and how this might impact HIV-1 transmission.

Work done by our group has highlighted the critical factors for successful mucosal transmission using a $\mathrm{Hu}$-mouse model. We demonstrated that the frequency of circulating human CD45 + cells was the primary determinant of successful HIV-1 infection following intravaginal exposure in HSC-engrafted NRG mice. Furthermore, a significant correlation existed between peripheral blood CD45+ cells and HIV-1 target cells in the vaginal mucosa (64). This study highlighted that for successful HIV-1 infection through the intravaginal route, access to target cells in the mucosa is required. This highlights the importance of developing prophylactic interventions that limit target cells in mucosa, such as limiting tissue inflammation (118), to prevent HIV-1 infection.

The role of the microbiota in altering HIV susceptibility is a growing area of interest and the subject of many clinical studies. Humice might be a useful model to examine the effect of the microbiota (vaginal and/or rectal) on HIV-1 acquisition, as a diverse vaginal microbiota low in Lactobacillus species is associated with a 4 -fold increased risk of acquisition in women (119). If the next generation of Hu-mouse models engrafted with HSCs could be developed as gnotobiotic (germ-free) mice, this would allow for the reconstitution of $\mathrm{Hu}$-mouse vagina/rectum/gut with human microbiota and assessment of HIV-1 acquisition risk. Although germ-free Humice are not presently commercially available, a recent publication reported the generation of "pseudo-gnotobiotic" $\mathrm{Hu}$ mice. NSG-BLT Hu-mice were treated with broad spectrum antibiotics, and subsequently transplanted with a human gut microbiota via fecal transplant; generating NSG-BLT mice reconstituted with human immune cells and a human gut microbiota. The authors found unique gut microbiota signatures in the mice that resembled those of the human donor, and they demonstrated that the human-like gut microbiota was stable in these mice for the duration of their study (14.5 weeks) (120). However, the relevance of this type of model and of other types of doubly-reconstituted Hu-mice (immune cells and microbiota) that we may be able to generate in the future is controversial at present. This is for a variety of reasons including, but not limited to, our lack of knowledge on generalizability of results obtained in mice to humans, a lack of standardized protocols, inter-donor, ethnic, and geographical microbial variability that makes replication of data challenging, and anatomical and physiological differences between mice and humans that might impact the microbiota (121). Nevertheless, germ-free humanized mouse models that can be reconstituted with a human-like microbiota may one day be key advancements that improve our understanding of the role of the vaginal, rectal and gut microbiota in mucosal HIV-1 transmission, epithelial barrier disruption, and inflammation. Furthermore, they may be useful in examining prophylactic interventions to decrease systemic inflammation and prevent HIV-1 transmission.

\section{USING HU-MICE FOR UNDERSTANDING TUBERCULOSIS-HIV CO-INFECTION}

Currently animal models for HIV co-infection with other pathogens are lacking. Although Hu-mice have been used to investigate HIV co-infection with pathogens such as Epstein-Barr virus and Neisseria gonorrhoeae $(30,122)$, co-infection with Mycobacterium tuberculosis (Mtb) is of particular interest as it is the most common cause of AIDS-related death (1). HIV-1 infection increases the risk of latent tuberculosis (TB) reactivation (123). HIV/TB co-infection increases morbidity and mortality while complicating therapies associated with both diseases due to multiple factors including the development of Immune Reconstitution Inflammatory Syndrome (IRIS) and TB drug resistance (124). The current inbred mouse in 
vivo models of TB do not develop organized granulomas (125) and show inconsistent immune responses (126).

On the other hand, the use of Hu-mouse models (HSCengrafted $(127,128)$ and BLT-engrafted (129) NSG mice) has demonstrated tremendous potential to recapitulate human TB infection, immune response, and formation of organized granulomas (127-129). With the vastly successful Hu-mice studies in HIV-1, they serve as a viable model for co-infection. In early HIV/TB co-infection studies, NSG-BLT mice were infected with HIV-1 followed by Mtb. HIV-1 was localized in pulmonary granulomas and exacerbated TB lesions and lung pathology were seen (130). A more recent study demonstrated that the same model can be used for studying TB relapse in co-infection by administration of HIV-1 intravenously after paucibacillary TB infection was established (131). Although only NSG-BLT model has been used thus far for TB-HIV co-infection, newer generation $\mathrm{Hu}$-mouse models using the easier and more accessible HSC-only engraftment method for HIV/Mtb co-infection would allow for more widespread use of the model, thus addressing the lack of literature on HIV/TB co-infection studies in vivo.

\section{IMPROVED HU-MOUSE MODELS FOR HIV-1 RESEARCH (NEXT GENERATION): NSG-A2, DRAG, DRAGA, AND BRGST}

\section{Addressing the Challenges With the BLT Model}

Even though the BLT model is currently the gold standard for HIV-1 research, there are several disadvantages that limit its use. Xenogenic GvHD that develops post-engraftment $(132,133)$ remains a concern despite efforts to extend longevity using a triple-knockout model $(134,135)$. This reduces the sample population of mice in studies (17) and prevents long-term studies. Humanized BLT mice also lack high levels of B cell populations and hyper-mutated, class-switched IgG antibodies (136). Furthermore, the engraftment of human fetal liver and thymus tissue is time-consuming and requires great technical skill to execute. Finally, a major issue with using the fetal BLT method is material availability, as restrictions on the use of fetal tissue in research is of increasing concern (137). To address this shortcoming, a novel method of using neonatal thymus tissue to replace the use of fetal tissue was developed within NOD, B6.SCIDIl2 $\mathrm{rg}^{-1-} \mathrm{Kit}^{\mathrm{W} 41 / \mathrm{W} 41}$ (NSGW) mice (NSGW-NeoThy) $(39,138)$. The addition of the Kit ${ }^{W 41 / W 41}$ alleles offers the advantage of accepting HSC engraftment without prior irradiation $(138,139)$. Neonatal thymic samples are easier to obtain, and yield much larger quantities of tissue and can thus humanize more mice per sample compared to using fetal tissue (39). NSGW-NeoThy mice developed smaller thymic organoids but with either autologous or allogeneic HSC engraftment, the model successfully repopulated human myeloid and lymphoid populations comparable to fetal thymus-only engrafted NSG mice (39), thus demonstrating its potential for future use in HIV investigations. Some evidence also presented the potential of reduced GvHD in NSGW-NeoThy mice by administration of anti-human CD2 antibodies to remove GVHD-associated passenger thymocytes, but a more comprehensive study must be conducted to elucidate GvHD development in the model (39).

\section{Next Generation of Transgenic Mice}

NSG-A2 mice were developed from the NSG background strain and are transgenic for the human HLA class I-A2 molecule. When humanized with HLA-matched HSCs, this allows human CD8+ T cells to be functionally mature (140). However, neither total CD8+ T cell reconstitution levels nor B cell function were significantly better than NSG mice $(140,141)$. To improve the humoral immune response, the HLA class II transgene (specifically, HLA-DR4) molecule has been expressed in the NOG (142), NSG (143), and NRG mice (34). Here we are focusing on the more popularly used and radiation-tolerant NRG background termed DRAG mice.

Humanized DRAG (hu-DRAG) mice with HSC derived HLA-DR-matched umbilical cord blood engraftment resulted in significantly higher counts of human CD4+ and CD8+ T cells compared to its non-transgenic NRG counterpart (34) (Table 1). Human B cells were highly functional, and could undergo immunoglobulin (Ig) isotype class-switching (34). To adequately compare the benefits between transgenic HLA class I and II, a model co-expressing both the HLA-A2 and HLA-DR4 molecules, termed DRAGA mice was developed (35). Comparisons between NRG-A2, DRAG, and DRAGA models engrafted with HLA-matched HSCs demonstrated that both huDRAG and hu-DRAGA models had significantly better human T-cell reconstitution, CD4/CD8 $+\mathrm{T}$ cell function, and most importantly, significant B cell Ig class-switching when compared to NRG-A2 mice (35) and even the hu-BLT models (136) (Table 1). These results demonstrate that the HLA-DR4 transgene can confer more benefits in human lymphoid reconstitution compared to HLA-A2.

Recently the BRG background was altered to produce a promising model with consistent lymph node reconstitution and development addressing the shortcomings of secondary lymphoid tissue formation within current Hu-mouse models $(37,144)$. Balb/

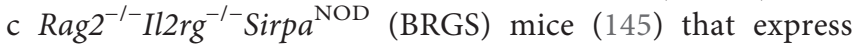
transgenic thymic-stromal-cell-derived lymphopoietin (TSLP), termed the BRGST model, boast robust human cellular and humoral responses (37). TSLP is similar in structure and function to IL-7, but is IL2rg independent and thus can promote $\mathrm{B}$ and $\mathrm{T}$ cell responses (39). In particular, when compared to the older hu-BRGS model, hu-BRGST mice demonstrated enhanced Ig-isotype class switching, central/ effector memory $\mathrm{T}$ cell, and $\mathrm{T}$ follicular helper (TFH) cell development in secondary lymphoid tissues with pronounced $\mathrm{B}$ cell zones (37). When the BRGS background hosts HLA class I and II transgenes (termed BRGSA2DR2 mice), improvements in $\mathrm{T}$ and $\mathrm{B}$ cell development and functionality including Ig-isotype class switching and antigen-specific responses were also observed (38).

Hu-DRAG mice are capable of supporting HIV-1 infections when challenged intravaginally as the mucosa of the FRT and gut both repopulate with CD4+ T cells and TFH cells $(36,146)$. HuBRGST mice successfully sustain HIV-1 infection and replication 
upon intraperitoneal inoculation (37). Viral reservoir and latency was also demonstrated after HAART administration, thus also offering possibilities in HIV latency and cure investigations (37). As hu-DRAG, hu-DRAGA, hu-BRGST, and hu-BRGSA2DR2 mice develop robust antigen-specific Ig responses, these models have tremendous potential for use in testing novel HIV-1 vaccine formulations. Immunization of both hu-DRAG and hu-DRAGA models for the investigation of other pathogenic viruses such as influenza $(35,147,148)$ and Zika (149) have already yielded promising results $(34,35,146-149)$. Therefore, the hu-DRAG and hu-DRAGA demonstrate tremendous potential for future use in HIV-1 therapeutic antibody and vaccine research.

\section{Other Novel Models for HIV-1 Studies}

The reconstituted human immune cell population in the current HSC-engrafted models for HIV-1 studies consist mainly of lymphoid cells with lower overall functional NK cell and myeloid repopulation (42, 150-152). Reduced myeloid populations may result in decreased endogenous cytokine signals, preventing the model from providing the full human inflammation process (42). Additionally, this may limit aspects of HIV-1 investigation such as innate immunity, antigen presentation interactions, or humoral immunity and vaccine studies. Table 1 summarizes some of the novel models including, MITRG/MISTRG models (discontinued by the Jackson Laboratory- short life span of 10-16 weeks post engraftment), NSGS (also called NSG-SGM3) model (NSG mice expressing human myeloid promoting cytokines SCF, GM-CSF, and IL-3, life span issue after 20 weeks) (42-44), and NOG-EXL (NOG mice expressing GM-CSF and IL-3) $(40,41)$ for better human myeloid cell engraftment of monocytes/macrophages and NK cells reconstitution $(46,47)$. Furthermore, the NSG-15 (45) and SRG-15 (31) models have been developed to express transgenic human IL-15 specifically for improved NK cell development. Overall, these models have all demonstrated success in their use for HIV-1 investigations, and their myeloid and NK reconstitution improvements can further extend HIV-1 in vivo research capabilities. It is important for researchers to note that until all shortcomings of Hu-mouse models have been addressed, choosing

\section{REFERENCES}

1. UNAIDS. 2019 fact sheet. Global HIV and AIDS statistics - 2019 fact sheet. (2020). Available at: https://www.unaids.org/en/resources/fact-sheet.

2. Bachmann N, von Siebenthal C, Vongrad V, Turk T, Neumann K, Beerenwinkel $\mathrm{N}$, et al. Determinants of HIV-1 reservoir size and longterm dynamics during suppressive ART. Nat Commun (2019) 10:1-11. doi: 10.1038/s41467-019-10884-9

3. Bell LCK, Noursadeghi M. Pathogenesis of HIV-1 and mycobacterium tuberculosis co-infection. Nat Rev Microbiol (2018) 16:80-90. doi: 10.1038/nrmicro.2017.128

4. Evans DT, Silvestri G. Nonhuman primate models in AIDS research. Curr Opin HIV AIDS (2013) 8:255-61. doi: 10.1097/COH.0b013e328361cee8

5. Sauter D, Kirchhoff F. Key Viral Adaptations Preceding the AIDS Pandemic. Cell Host Microbe (2019) 25:27-38. doi: 10.1016/j.chom.2018.12.002

6. Hatziioannou T, Evans DT. Animal models for HIV/AIDS research. Nat Rev Microbiol (2012) 10:852-67. doi: 10.1038/nrmicro2911

7. Shultz LD, Brehm MA, Victor Garcia-Martinez J, Greiner DL. Humanized mice for immune system investigation: Progress, promise and challenges. Nat Rev Immunol (2012) 12:786-98. doi: 10.1038/nri3311 the optimal model for a study will depend on the experiment itself with special considerations for study timeline and immune cells of interest.

\section{CONCLUSION}

In summary, the development of Hu-mouse models has provided a cost-effective and practical approach for HIV-1 research. These mice provide a useful pre-clinical tool, since they allow researchers to directly examine interactions between HIV-1 and the human immune system. Novel modifications in generating Hu-mice is increasing the feasibility of using these models to investigate more complex clinical problems, such as immune response in co-infections like HIV and TB, and understanding interactions between immune responses and microbiota in regulating HIV-1 susceptibility. As we continue to make improvements in humanization of mice by developing novel models with new features and gain better understanding of how to tailor the models to answer specific questions, we will continue to push the envelope and make breakthroughs in HIV1 research.

\section{AUTHOR CONTRIBUTIONS}

AG and CK outlined the content of the review. JY and JW prepared the main body of the manuscript. AG and CK revised the manuscript. AG supervised the project. All authors contributed to the article and approved the submitted version.

\section{FUNDING}

CK's laboratory is funded by the Canadian Institutes of Health Research Operating Grant (FRN\# SOP 159229). Salary support (JW) is provided by a Canadian Institutes of Health Research Postdoctoral Fellowship award (MFE 152502).

8. Hladik F, McElrath MJ. Setting the stage: Host invasion by HIV. Nat Rev Immunol (2008) 8:447-57. doi: 10.1038/nri2302

9. Brehm MA, Cuthbert A, Yang C, Miller DM, DiIorio P, Laning J, et al. Parameters for establishing humanized mouse models to study human immunity: Analysis of human hematopoietic stem cell engraftment in three immunodeficient strains of mice bearing the IL2rynull mutation. Clin Immunol (2010) 135:84-98. doi: 10.1016/j.clim.2009.12.008

10. Shultz LD, Lyons BL, Burzenski LM, Gott B, Chen X, Chaleff S, et al. Human Lymphoid and Myeloid Cell Development in NOD/LtSz- scid IL2R $\gamma$ null Mice Engrafted with Mobilized Human Hemopoietic Stem Cells. J Immunol (2005) 174:6477-89. doi: 10.4049/jimmunol.174.10.6477

11. McDermott SP, Eppert K, Lechman ER, Doedens M, Dick JE. Comparison of human cord blood engraftment between immunocompromised mouse strains. Blood (2010) 116:193-200. doi: 10.1182/blood-2010-02-271841

12. Pearson T, Shultz LD, Miller D, King M, Laning J, Fodor W, et al. Non-obese diabetic-recombination activating gene-1 (NOD-Rag1 null) interleukin (IL)2 receptor common gamma chain (IL2rynull) null mice: A radioresistant model for human lymphohaematopoietic engraftment. Clin Exp Immunol (2008) 154:270-84. doi: 10.1111/j.1365-2249.2008.03753.x 
13. Cao X, Shores EW, Hu-LI J, Ft Anver M, Kelsall BL, SM R, et al. Defective Lymphoid Development in Mice Lacking Expression of the Common Cytokine Receptor y Chain. Immunity (1995) 2:223-8. doi: 10.1016/1074-7613(95)90047-0

14. Pearson T, Greiner DL, Shultz LD. Creation of "humanized" Mice to study human immunity. Curr Protoc Immunol (2008) 81:15.21.1-15.21.21. doi: 10.1002/0471142735.im1521s81

15. Hayakawa J, Hsieh MM, Uchida N, Phang O, Tisdale JF. Busulfan Produces Efficient Human Cell Engraftment in NOD/LtSz- Scid IL2R $\gamma$ Null Mice. Stem Cells (2009) 27:175-82. doi: 10.1634/stemcells.2008-0583

16. Sato K, Nie C, Misawa N, Tanaka Y, Ito M, Koyanagi Y. Dynamics of memory and naïve CD8+ T lymphocytes in humanized NOD/SCID/IL2R $\gamma$ null mice infected with CCR5-tropic HIV-1. Vaccine (2010) 28:B32-7. doi: 10.1016/j.vaccine.2009.10.154

17. Karpel ME, Boutwell CL, Allen TM. BLT humanized mice as a small animal model of HIV infection. Curr Opin Virol (2015) 13:75-80. doi: 10.1016/ j.coviro.2015.05.002

18. Brainard DM, Seung E, Frahm N, Cariappa A, Bailey CC, Hart WK, et al. Induction of Robust Cellular and Humoral Virus-Specific Adaptive Immune Responses in Human Immunodeficiency Virus-Infected Humanized BLT Mice. J Virol (2009) 83:7305-21. doi: 10.1128/jvi.02207-08

19. Lan P, Tonomura N, Shimizu A, Wang S, Yang YG. Reconstitution of a functional human immune system in immunodeficient mice through combined human fetal thymus/liver and CD34+ cell transplantation. Blood (2006) 108:487-92. doi: 10.1182/blood-2005-11-4388

20. Smith DJ, Lin LJ, Moon H, Pham AT, Wang X, Liu S, et al. Propagating Humanized BLT Mice for the Study of Human Immunology and Immunotherapy. Stem Cells Dev (2016) 25:1863-73. doi: 10.1089/scd.2016.0193

21. Cheng L, Ma J, Li G, Su L. Humanized mice engrafted with human HSC only or HSC and thymus support comparable HIV-1 replication, immunopathology, and responses to ART and immune therapy. Front Immunol (2018) 9:817-3. doi: 10.3389/fimmu.2018.00817

22. Denton PW, Nochi T, Lim A, Krisko JF, Martinez-Torres F, Choudhary SK, et al. IL-2 receptor $\gamma$-chain molecule is critical for intestinal T-cell reconstitution in humanized mice. Mucosal Immunol (2012) 5:555-66. doi: 10.1038/mi.2012.31

23. Nochi T, Denton PW, Wahl A, Garcia JV. Cryptopatches Are Essential for the Development of Human GALT. Cell Rep (2013) 3:1874-84. doi: 10.1016/ j.celrep.2013.05.037

24. Berges BK, Akkina SR, Folkvord JM, Connick E, Akkina R. Mucosal transmission of R5 and $\mathrm{X} 4$ tropic $\mathrm{HIV}-1$ via vaginal and rectal routes in humanized Rag2-/- $\gamma$ c-/- (RAG-hu) mice. Virology (2008) 373:342-51. doi: 10.1016/j.virol.2007.11.020

25. Sango K, Joseph A, Patel M, Osiecki K, Dutta M, Goldstein H. Highly active antiretroviral therapy potently suppresses HIV infection in humanized

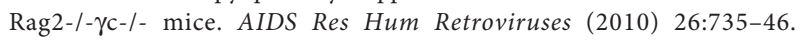
doi: 10.1089/aid.2009.0136

26. Jiang Q, Zhang L, Wang R, Jeffrey J, Washburn ML, Brouwer D, et al. FoxP3 $+\mathrm{CD} 4+$ regulatory $\mathrm{T}$ cells play an important role in acute HIV-1 infection in humanized Rag2-/-\{gamma\}C-/-mice in vivo. Blood (2008) 112:2858-68. doi: 10.1182/blood-2008-03-145946

27. Traggiai E, Chicha L, Mazzucchelli L, Bronz L, Piffaretti J-C, Lanzavecchia A, et al. Development of a Human Adaptive Immune System in Cord Blood Cell-Transplanted Mice. (2004) 304:104-7. doi: 10.1126/science.10939330

28. Watanabe Y, Takahashi T, Okajima A, Shiokawa M, Ishii N, Katano I, et al. The analysis of the functions of human B and T cells in humanized NOD/ shi-scid/ $\gamma$ cnull (NOG) mice (hu-HSC NOG mice). Int Immunol (2009) 21:843-58. doi: 10.1093/intimm/dxp050

29. Satheesan S, Li H, Burnett JC, Takahashi M, Li S, Wu SX, et al. HIV Replication and Latency in a Humanized NSG Mouse Model during Suppressive Oral Combinational Antiretroviral Therapy. J Virol (2018) 92: e02118-17. doi: 10.1128/jvi.02118-17

30. Xu SX, Leontyev D, Kaul R, Gray-Owen SD. Neisseria gonorrhoeae coinfection exacerbates vaginal HIV shedding without affecting systemic viral loads in human CD34+ engrafted mice. PloS One (2018) 13:e0191672. doi: 10.1371/journal.pone.0191672

31. Herndler-Brandstetter D, Shan L, Yao Y, Stecher C, Plajer V, Lietzenmayer $\mathrm{M}$, et al. Humanized mouse model supports development, function, and tissue residency of human natural killer cells. Proc Natl Acad Sci USA (2017) 114:E9626-34. doi: 10.1073/pnas.1705301114
32. Denton PW, Estes JD, Sun Z, Othieno FA, Wei BL, Wege AK, et al. Antiretroviral Pre-exposure Prophylaxis Prevents Vaginal Transmission of HIV-1 in Humanized BLT Mice. PloS Med (2008) 5:e16. doi: 10.1371/ journal.pmed.0050016

33. Sun Z, Denton PW, Estes JD, Othieno FA, Wei BL, Wege AK, et al. Intrarectal transmission, systemic infection, and $\mathrm{CD} 4+\mathrm{T}$ cell depletion in humanized mice infected with HIV-1. J Exp Med (2007) 204:705-14. doi: $10.1084 /$ jem.20062411

34. Danner R, Chaudhari SN, Rosenberger J, Surls J, Richie TL, Brumeanu TD, et al. Expression of HLA class II molecules in humanized NOD.Rag1KO.IL2RgcKO mice is critical for development and function of human T and B cells. PloS One (2011) 6:e19826. doi: 10.1371/journal.pone.0019826

35. Majji S, Wijayalath W, Shashikumar S, Pow-Sang L, Villasante E, Brumeanu TD, et al. Differential effect of HLA class-I versus class-II transgenes on human $\mathrm{T}$ and B cell reconstitution and function in NRG mice. Sci Rep (2016) 6:1-13. doi: 10.1038/srep28093

36. Allam A, Majji S, Peachman K, Jagodzinski L, Kim J, Ratto-Kim S, et al. TFH cells accumulate in mucosal tissues of humanized-DRAG mice and are highly permissive to HIV-1. Sci Rep (2015) 5:10443-16. doi: 10.1038/srep10443

37. Li Y, Masse-Ranson G, Garcia Z, Bruel T, Kök A, Strick-Marchand H, et al. A human immune system mouse model with robust lymph node development. Nat Methods (2018) 15:623-30. doi: 10.1038/s41592-018-0071-6

38. Masse-Ranson G, Dusséaux M, Fiquet O, Darche S, Boussand M, Li Y, et al. Accelerated thymopoiesis and improved T-cell responses in HLA-A2/-DR2 transgenic BRGS-based human immune system mice. Eur J Immunol (2019) 49:954-65. doi: 10.1002/eji.201848001

39. Brown ME, Zhou Y, McIntosh BE, Norman IG, Lou HE, Biermann M, et al. A Humanized Mouse Model Generated Using Surplus Neonatal Tissue. Stem Cell Rep (2018) 10:1175-83. doi: 10.1016/j.stemcr.2018.02.011

40. Ito R, Takahashi T, Katano I, Kawai K, Kamisako T, Ogura T, et al. Establishment of a Human Allergy Model Using Human IL-3/GM-CSFTransgenic NOG Mice. J Immunol (2013) 191:2890-9. doi: 10.4049/ jimmunol.1203543

41. Perdomo-Celis F, Medina-Moreno S, Davis H, Bryant J, Zapata JC. HIV Replication in Humanized IL-3/GM-CSF-Transgenic NOG Mice. Pathogens (2019) 8:33-16. doi: 10.3390/pathogens8010033

42. Yoshihara S, Li Y, Xia J, Danzl N, Sykes M, Yang YG. Posttransplant hemophagocytic lymphohistiocytosis driven by myeloid cytokines and vicious cycles of T-cell and macrophage activation in humanized mice. Front Immunol (2019) 10:186. doi: 10.3389/fimmu.2019.00186

43. Billerbeck E, Barry WT, Mu K, Dorner M, Rice CM, Ploss A. Development of human $\mathrm{CD} 4+\mathrm{FoxP} 3+$ regulatory $\mathrm{T}$ cells in human stem cell factor-, granulocyte-macrophage colony-stimulating factor-, and interleukin-3expressing NOD-SCID IL2R $\gamma$ null humanized mice. Blood (2011) 117:3076-86. doi: 10.1182/blood-2010-08-301507

44. Wunderlichid M, Chouid F-S, Sexton C, Presicceid P, Chougnet CA, Aliberti J, et al. Improved multilineage human hematopoietic reconstitution and function in NSGS mice. PLoS One (2018) 13:e0209034. doi: 10.1371/ journal.pone.0209034

45. Matsuda M, Ono R, Iyoda T, Endo T, Iwasaki M, Tomizawa-Murasawa M, et al. Human NK cell development in hIL-7 and hIL-15 knockin NOD/ SCID/IL2rgKO mice. Life Sci Alliance (2019) 2:e201800195. doi: 10.26508/ lsa. 201800195

46. Rongvaux A, Willinger T, Martinek J, Strowig T, Gearty SV, Teichmann LL, et al. Development and function of human innate immune cells in a humanized mouse model HHS Public Access Author manuscript. Nat Biotechnol (2014) 32:364-72. doi: 10.1038/nbt.2858

47. Ivic S, Rochat M-A, Li D, Audigé A, Schlaepfer E, Münz C, et al. Differential Dynamics of HIV Infection in Humanized MISTRG versus MITRG Mice. ImmunoHorizons (2017) 1:162-75. doi: 10.4049/immunohorizons.1700042

48. Tonomura N, Habiro K, Shimizu A, Sykes M, Yang YG. Antigen-specific human $\mathrm{T}$-cell responses and $\mathrm{T}$ cell-dependent production of human antibodies in a humanized mouse model. Blood (2008) 111:4293-6. doi: 10.1182/blood-2007-11-121319

49. Denton PW, García JV. Humanized mouse models of HIV infection. AIDS $\operatorname{Rev}(2011)$ 13:135-48.

50. Garcia V. Humanized mice for HIV and AIDS research. Curr Opin Virol (2016) 19:56-64. doi: 10.1016/j.coviro.2016.06.010 
51. Watanabe S, Ohta S, Yajima M, Terashima K, Ito M, Mugishima $\mathrm{H}$, et al. Humanized NOD/SCID/IL2R null Mice Transplanted with Hematopoietic Stem Cells under Nonmyeloablative Conditions Show Prolonged Life Spans and Allow Detailed Analysis of Human Immunodeficiency Virus Type 1 Pathogenesis. J Virol (2007) 81:13259-64. doi: 10.1128/jvi.01353-07

52. Nie C, Sato K, Misawa N, Kitayama H, Fujino H, Hiramatsu H, et al. Selective infection of CD4+ effector memory $\mathrm{T}$ lymphocytes leads to preferential depletion of memory T lymphocytes in R5 HIV-1-infected humanized NOD/SCID/IL-2R rnull mice. Virology (2009) 394:64-72. doi: 10.1016/j.virol.2009.08.011

53. Gorantla S, Makarov E, Finke-Dwyer J, Gebhart CL, Domm W, Dewhurst S, et al. CD8 + Cell Depletion Accelerates HIV-1 Immunopathology in Humanized Mice. J Immunol (2010) 184:7082-91. doi: 10.4049/jimmunol.1000438

54. Kim KC, Choi BS, Kim KC, Park KH, Lee HJ, Cho YK, et al. A Simple Mouse Model for the Study of Human Immunodeficiency Virus. AIDS Res Hum Retroviruses (2016) 32:194-202. doi: 10.1089/aid.2015.0211

55. Nakano Y, Misawa N, Juarez-Fernandez G, Moriwaki M, Nakaoka S, Funo T, et al. HIV-1 competition experiments in humanized mice show that APOBEC3H imposes selective pressure and promotes virus adaptation. PloS Pathog (2017) 13:e1006348. doi: 10.1371/journal.ppat.1006348

56. Perez EE, Wang J, Miller JC, Jouvenot Y, Kim KA, Liu O, et al. Establishment of HIV-1 resistance in CD4+ T cells by genome editing using zinc-finger nucleases. Nat Biotechnol (2008) 26:808-16. doi: 10.1038/nbt1410

57. Sato K, Misawa N, Takeuchi JS, Kobayashi T, Izumi T, Aso H, et al. Experimental adaptive evolution of SIVcpz to pandemic HIV-1 using a humanized mouse model. J Virol (2017) 92:JVI.01905-17. doi: 10.1128/jvi.01905-17

58. Nischang M, Sutmuller R, Gers-Huber G, Audigé A, Li D, Rochat MA, et al. Humanized mice recapitulate key features of HIV-1 infection: A novel concept using long-acting anti-retroviral drugs for treating HIV-1. PloS One (2012) 7:e38853. doi: 10.1371/journal.pone.0038853

59. Rochat MA, Schlaepfer E, Kuster SP, Li D, Audige A, Ivic S, et al. Monitoring HIV DNA and cellular activation markers in HIV-infected humanized mice under cART. Virol J (2018) 15:191-8. doi: 10.1186/s12985-018-1101-9

60. Khamaikawin W, Shimizu S, Kamata M, Cortado R, Jung Y, Lam J, et al. Modeling Anti-HIV-1 HSPC-Based Gene Therapy in Humanized Mice Previously Infected with HIV-1. Mol Ther - Methods Clin Dev (2018) 9:23-32. doi: 10.1016/j.omtm.2017.11.008

61. Dash PK, Kaminski R, Bella R, Su H, Mathews S, Ahooyi TM, et al. Sequential LASER ART and CRISPR Treatments Eliminate HIV-1 in a Subset of Infected Humanized Mice. Nat Commun (2019) 10:2753-20. doi: 10.1038/s41467-019-10366-y

62. Law KM, Komarova NL, Yewdall AW, Lee RK, Herrera OL, Wodarz D, et al. In Vivo HIV-1 Cell-to-Cell Transmission Promotes Multicopy Microcompartmentalized Infection. Cell Rep (2016) 15:2771-83. doi: 10.1016/ j.celrep.2016.05.059

63. Su H, Cheng Y, Sravanam S, Mathews S, Gorantla S, Poluektova LY, et al. Immune Activations and Viral Tissue Compartmentalization During Progressive HIV-1 Infection of Humanized Mice. Front Immunol (2019) 10:340-17. doi: 10.3389/fimmu.2019.00340

64. Nguyen PV, Wessels JM, Mueller K, Vahedi F, Anipindi V, Verschoor CP, et al. Frequency of Human CD45+ Target Cells is a Key Determinant of Intravaginal HIV-1 Infection in Humanized Mice. Sci Rep (2017) 7:1526315. doi: 10.1038/s41598-017-15630-z

65. Wessels JM, Lajoie J, Hay Cooper MIJ, Omollo K, Felker AM, Vitali D, et al. Medroxyprogesterone acetate alters the vaginal microbiota and microenvironment in women and increases susceptibility to HIV-1 in humanized mice. DMM Dis Model Mech (2019) 12:dmm039669. doi: $10.1242 / \mathrm{dmm} .039669$

66. Goldman JP, Blundell MP, Lopes L, Kinnon C, DI Santo JP, Thrasher AJ. Enhanced human cell engraftment in mice deficient in RAG2 and the common cytokine receptor gamma chain. Br J Haematol (1998) 103:33542. doi: 10.1046/j.1365-2141.1998.00980.x

67. Neff CP, Ndolo T, Tandon A, Habu Y, Akkina R. Oral Pre-Exposure Prophylaxis by Anti-Retrovirals Raltegravir and Maraviroc Protects against HIV-1 Vaginal Transmission in a Humanized Mouse Model. PloS One (2010) 5:e15257. doi: 10.1371/journal.pone.0015257

68. Choudhary SK, Rezk NL, Ince WL, Cheema M, Zhang L, Su L, et al. Suppression of Human Immunodeficiency Virus Type 1 (HIV-1) Viremia with Reverse Transcriptase and Integrase Inhibitors, CD4+ T-Cell Recovery, and Viral Rebound upon Interruption of Therapy in a New Model for HIV Treatment in the Humanized Rag2-/- c-/- Mouse. J Virol (2009) 83:8254-8. doi: 10.1128/jvi.00580-09

69. Schmitt K, Mohan Kumar D, Curlin J, Remling-Mulder L, Stenglein M, O'Connor S, et al. Modeling the evolution of SIV sooty mangabey progenitor virus towards HIV-2 using humanized mice. Virology (2017) 510:175-84. doi: 10.1016/j.virol.2017.07.005

70. Schmitt K, Curlin J, Remling-Mulder L, Moriarty R, Goff K, O'Connor S, et al. Cross-Species Transmission and Evolution of SIV Chimpanzee Progenitor Viruses Toward HIV-1 in Humanized Mice. Front Microbiol (2020) 11:1889:1889. doi: 10.3389/fmicb.2020.01889

71. Charlins P, Schmitt K, Remling-Mulder L, Hogan LE, Hanhauser E, Hobbs KS, et al. A humanized mouse-based HIV-1 viral outgrowth assay with higher sensitivity than in vitro qVOA in detecting latently infected cells from individuals on ART with undetectable viral loads. Virology (2017) 507:1359. doi: 10.1016/j.virol.2017.04.011

72. Schmitt K, Akkina R. Ultra-sensitive HIV-1 latency viral outgrowth assays using humanized mice. Front Immunol (2018) 9:344. doi: 10.3389/ fimmu.2018.00344

73. Veselinovic M, Yang KH, LeCureux J, Sykes C, Remling-Mulder L, Kashuba $\mathrm{ADM}$, et al. HIV pre-exposure prophylaxis: Mucosal tissue drug distribution of RT inhibitor Tenofovir and entry inhibitor Maraviroc in a humanized mouse model. Virology (2014) 464-465:253-63. doi: 10.1016/j.virol.2014.07.008

74. Veselinovic M, Yang KH, Sykes C, Remling-Mulder L, Kashuba ADM, Akkina R. Mucosal tissue pharmacokinetics of the integrase inhibitor raltegravir in a humanized mouse model: Implications for HIV pre-exposure prophylaxis. Virology (2016) 489:173-8. doi: 10.1016/j.virol.2015.12.014

75. Neff CP, Kurisu T, Ndolo T, Fox K, Akkina R. A Topical Microbicide Gel Formulation of CCR5 Antagonist Maraviroc Prevents HIV-1 Vaginal Transmission in Humanized RAG-hu Mice. PloS One (2011) 6:e20209. doi: 10.1371/journal.pone.0020209

76. Veselinovic M, Preston Neff C, Mulder LR, Akkina R. Topical gel formulation of broadly neutralizing anti-HIV-1 monoclonal antibody VRC01 confers protection against HIV-1 vaginal challenge in a humanized mouse model. Virology (2012) 432:505-10. doi: 10.1016/ j.virol.2012.06.025

77. Li G, Cheng M, Nunoya JI, Cheng L, Guo H, Yu H, et al. Plasmacytoid Dendritic Cells Suppress HIV-1 Replication but Contribute to HIV-1 Induced Immunopathogenesis in Humanized Mice. PloS Pathog (2014) 10:e1004291. doi: 10.1371/journal.ppat.1004291

78. Cheng L, Ma J, Li J, Li D, Li G, Li F, et al. Blocking type I interferon signaling enhances T cell recovery and reduces HIV-1 reservoirs. J Clin Invest (2017) 127:269-79. doi: 10.1172/JCI90745

79. Lu CL, Murakowski DK, Bournazos S, Schoofs T, Sarkar D, HalperStromberg A, et al. Enhanced clearance of HIV-1-infected cells by broadly neutralizing antibodies against HIV-1 in vivo. Sci (80- ) (2016) 352:1001-4. doi: 10.1126/science.aaf1279

80. Abela IA, Berlinger L, Schanz M, Reynell L, Günthard HF, Rusert P, et al. Cell-cell transmission enables HIV-1 to evade inhibition by potent CD4bs directed antibodies. PloS Pathog (2012) 8:e1002634. doi: 10.1371/ journal.ppat.1002634

81. Klein F, Halper-Stromberg A, Horwitz JA, Gruell H, Scheid JF, Bournazos S, et al. HIV therapy by a combination of broadly neutralizing antibodies in humanized mice. Nature (2012) 492:118-22. doi: 10.1038/nature1 1604

82. Bella R, Kaminski R, Mancuso P, Young WB, Chen C, Sariyer R, et al. Removal of HIV DNA by CRISPR from Patient Blood Engrafts in Humanized Mice. Mol Ther - Nucleic Acids (2018) 12:275-82. doi: 10.1016/j.omtn.2018.05.021

83. Cheng L, Yu H, Wrobel JA, Li G, Liu P, Hu Z, et al. Identification of pathogenic TRAIL-expressing innate immune cells during HIV-1 infection in humanized mice by scRNA-Seq. JCI Insight (2020) 5:e135344. doi: 10.1172/jci.insight.135344

84. Godot V, Tcherakian C, Gil L, Cervera-Marzal I, Li G, Cheng L, et al. TLR-9 agonist and CD40-targeting vaccination induces HIV-1 envelope-specific B cells with a diversified immunoglobulin repertoire in humanized mice. PloS Pathog (2020) 16:e1009025. doi: 10.1371/journal.ppat.1009025

85. Wahl A, Garcia V. The use of BLT humanized mice to investigate the immune reconstitution of the gastrointestinal tract. J Immunol Methods (2014) 410:28-33. doi: 10.1016/j.jim.2014.06.009 
86. Skelton JK, Ortega-Prieto AM. Dorner M. A Hitchhiker's guide to humanized mice: new pathways to studying viral infections. Immunology (2018) 154:50-61. doi: 10.1111/imm.12906

87. Denton PW, Krisko JF, Powell DA, Mathias M, Kwak YT, Martinez-Torres F, et al. Systemic Administration of Antiretrovirals Prior to Exposure Prevents Rectal and Intravenous HIV-1 Transmission in Humanized BLT Mice. PloS One (2010) 5:e8829. doi: 10.1371/journal.pone.0008829

88. Kovarova M, Swanson MD, Sanchez RI, Baker CE, Steve J, Spagnuolo RA, et al. Victor Garcia J. A long-acting formulation of the integrase inhibitor raltegravir protects humanized BLT mice from repeated high-dose vaginal HIV challenges. J Antimicrob Chemother (2016) 71:1586-96. doi: 10.1093/jac/dkw042

89. Kovarova M, Benhabbour SR, Massud I, Spagnuolo RA, Skinner B, Baker $\mathrm{CE}$, et al. Ultra-long-acting removable drug delivery system for HIV treatment and prevention. Nat Commun (2018) 9:4156-11. doi: 10.1038/ s41467-018-06490-w

90. Shanmugasundaram U, Kovarova M, Ho PT, Schramm N, Wahl A, Parniak MA, et al. Efficient inhibition of HIV replication in the gastrointestinal and female reproductive tracts of humanized BLT mice by EFdA. PloS One (2016) 11:e0159517. doi: 10.1371/journal.pone.0159517

91. Chateau ML, Denton PW, Swanson MD, McGowan I, Garcia JV. Rectal Transmission of Transmitted/Founder HIV-1 Is Efficiently Prevented by Topical 1\% Tenofovir in BLT Humanized Mice. PloS One (2013) 8:e60024. doi: 10.1371/journal.pone.0060024

92. Council OD, Swanson MD, Spagnuolo RA, Wahl A, Garcia JV. Role of semen on vaginal HIV-1 transmission and maraviroc protection. Antimicrob Agents Chemother (2015) 59:7847-51. doi: 10.1128/AAC.01496-15

93. Sun M, Li Y, Yuan Z, Lu W, Kang G, Fan W, et al. VRC01 antibody protects against vaginal and rectal transmission of human immunodeficiency virus 1 in hu-BLT mice. Arch Virol (2016) 161:2449-55. doi: 10.1007/s00705-016-2942-4

94. Balazs AB, Ouyang Y, Hong CM, Chen J, Nguyen SM, Rao DS, et al. Vectored immunoprophylaxis protects humanized mice from mucosal HIV transmission. Nat Med (2014) 20:296-300. doi: 10.1038/nm.3471

95. Yuan Z, Kang G, Ma F, Lu W, Fan W, Fennessey CM, et al. Recapitulating Cross-Species Transmission of Simian Immunodeficiency Virus SIVcpz to Humans by Using Humanized BLT Mice. J Virol (2016) 90:7728-39. doi: 10.1128/jvi.00860-16

96. Zhen A, Rezek V, Youn C, Lam B, Chang N, Rick J, et al. Targeting type I interferon-mediated activation restores immune function in chronic HIV infection. J Clin Invest (2017) 127:260-8. doi: 10.1172/JCI89488

97. Zhen A, Kamata M, Rezek V, Rick J, Levin B, Kasparian S, et al. HIV-specific Immunity Derived from Chimeric Antigen Receptor-engineered Stem Cells. Mol Ther (2015) 23:1358-67. doi: 10.1038/mt.2015.102

98. Maidji E, Moreno ME, Rivera JM, Joshi P, Galkina SA, Kosikova G, et al. Cellular HIV reservoirs and viral rebound from the lymphoid compartments of 40-Ethynyl-2-Fluoro-20-Deoxyadenosine (EFdA)-suppressed humanized mice. Viruses (2019) 11:256-27. doi: 10.3390/v11030256

99. Tsai P, Wu G, Baker CE, Thayer WO, Spagnuolo RA, Sanchez R, et al. In vivo analysis of the effect of panobinostat on cell-associated HIV RNA and DNA levels and latent HIV infection. Retrovirology (2016) 13:36-12. doi: 10.1186/s12977-016-0268-7

100. Claiborne DT, Dudek TE, Maldini CR, Power KA, Ghebremichael M, Seung E, et al. Immunization of BLT Humanized Mice Redirects T Cell Responses to Gag and Reduces Acute HIV-1 Viremia. J Virol (2019) 93: e00814-19. doi: 10.1128/jvi.00814-19

101. Norton TD, Zhen A, Tada T, Kim J, Kitchen S, Landau NR. Lentiviral VectorBased Dendritic Cell Vaccine Suppresses HIV Replication in Humanized Mice. Mol Ther (2019) 27:960-73. doi: 10.1016/j.ymthe.2019.03.008

102. Cheng L, Wang Q, Li G, Banga R, Ma J, Yu H, et al. TLR3 agonist and CD40targeting vaccination induces immune responses and reduces HIV-1 reservoirs. J Clin Invest (2018) 128:4387-96. doi: 10.1172/JCI99005

103. Haase AT. Targeting early infection to prevent HIV-1 mucosal transmission. Nature (2010) 464:217-23. doi: 10.1038/nature08757

104. Estes JD, Wong SW, Brenchley JM. Nonhuman primate models of human viral infections. Nat Rev Immunol (2018) 18:390-404. doi: 10.1038/s41577018-0005-7

105. Brenchley JM, Douek DC. The mucosal barrier and immune activation in HIV pathogenesis. Curr Opin HIV AIDS (2008) 3:356-61. doi: 10.1097/ COH.0b013e3282f9ae9c
106. Denton PW, Garcia JV. Mucosal HIV-1 transmission and prevention strategies in BLT humanized mice. Trends Microbiol (2012) 20:268-74. doi: 10.1016/j.tim.2012.03.007

107. Gallay PA, Chatterji U, Kirchhoff A, Gandarilla A, Pyles RB, Baum MM, et al. Protection Efficacy of C5A Against Vaginal and Rectal HIV Challenges in Humanized Mice. Open Virol J (2018) 12:1-13. doi: 10.2174/ 1874357901812010001

108. Gallay PA, Chatterji U, Kirchhoff A, Gandarilla A, Gunawardana M, Pyles $\mathrm{RB}$, et al. Prevention of vaginal and rectal HIV transmission by antiretroviral combinations in humanized mice. PloS One (2017) 12:e184303. doi: 10.1371/journal.pone.0184303

109. Wheeler LA, Vrbanac V, Trifonova R, Brehm MA, Gilboa-Geffen A, Tanno S, et al. Durable knockdown and protection from HIV transmission in humanized mice treated with gel-formulated CD4 aptamer-siRNA chimeras. Mol Ther (2013) 21:1378-89. doi: 10.1038/mt.2013.77

110. Denton PW, Othieno F, Martinez-Torres F, Zou W, Krisko JF, Fleming E, et al. One Percent Tenofovir Applied Topically to Humanized BLT Mice and Used According to the CAPRISA 004 Experimental Design Demonstrates Partial Protection from Vaginal HIV Infection, Validating the BLT Model for Evaluation of New Microbicide Candidates. J Virol (2011) 85:7582-93. doi: 10.1128/jvi.00537-11

111. Wheeler LA, Trifonova R, Vrbanac V, Basar E, McKernan S, Xu Z, et al. Inhibition of HIV transmission in human cervicovaginal explants and humanized mice using CD4 aptamer-siRNA chimeras. J Clin Invest (2011) 121:2401-12. doi: 10.1172/JCI45876

112. Destache CJ, Mandal S, Yuan Z, Kang G, Date AA, Lu W, et al. Topical tenofovir disoproxil fumarate nanoparticles prevent HIV-1 vaginal transmission in a humanized mouse model. Antimicrob Agents Chemother (2016) 60:3633-9. doi: 10.1128/AAC.00450-16

113. Farr Zuend C, Nomellini JF, Smit J, Horwitz MS. A Caulobacter crescentus Microbicide Protects from Vaginal Infection with HIV-1 JR-CSF in Humanized Bone Marrow-Liver-Thymus Mice. J Virol (2019) 93:e0061419. doi: 10.1128/jvi.00614-19

114. Kovarova M, Council OD, Date AA, Long JM, Nochii T, Belshan M, et al. Nanoformulations of Rilpivirine for Topical Pericoital and Systemic CoitusIndependent Administration Efficiently Prevent HIV Transmission. PloS Pathog (2015) 11:e1005075-e1005075. doi: 10.1371/journal.ppat.1005075

115. Melody K, Roy CN, Kline C, Cottrell ML, Evans D, Shutt K, et al. Long-Acting Rilpivirine (RPV) Preexposure Prophylaxis Does Not Inhibit Vaginal Transmission of RPV-Resistant HIV-1 or Select for High-Frequency Drug Resistance in Humanized Mice. J Virol (2020) 94:1912-31. doi: 10.1128/jvi.01912-19

116. Sepúlveda-Crespo D, Serramía MJ, Tager AM, Vrbanac V, Gómez R, De La Mata FJ, et al. Prevention vaginally of HIV-1 transmission in humanized BLT mice and mode of antiviral action of polyanionic carbosilane dendrimer G2-S16. Nanomed Nanotechnol Biol Med (2015) 11:1299-308. doi: 10.1016/j.nano.2015.04.013

117. Mandal S, Prathipati PK, Kang G, Zhou Y, Yuan Z, Fan W, et al. Tenofovir alafenamide and elvitegravir loaded nanoparticles for long-acting prevention of HIV-1 vaginal transmission. AIDS (2017) 31:469-76. doi: 10.1097/ QAD.0000000000001349

118. Ferreira VH, Kafka JK, Kaushic C. Influence of Common Mucosal CoFactors on HIV Infection in the Female Genital Tract. Am J Reprod Immunol (2014) 71:543-54. doi: 10.1111/aji.12221

119. Gosmann C, Anahtar MN, Handley SA, Farcasanu M, Abu-Ali G, Bowman BA, et al. Lactobacillus-Deficient Cervicovaginal Bacterial Communities Are Associated with Increased HIV Acquisition in Young South African Women. Immunity (2017) 46:29-37. doi: 10.1016/j.immuni.2016.12.013

120. Daharsh L, Zhang J, Ramer-Tait A, Li Q. A double humanized blt-mice model featuring a stable human-like gut microbiome and human immune system. J Vis Exp (2019) 150:e59773. doi: 10.3791/59773

121. Park JC, Im SH. Of men in mice: the development and application of a humanized gnotobiotic mouse model for microbiome therapeutics. Exp Mol Med (2020) 52:1383-96. doi: 10.1038/s12276-020-0473-2

122. McHugh D, Myburgh R, Caduff N, Spohn M, Kok YL, Keller CW, et al. EBV renders B cells susceptible to HIV-1 in humanized mice. Life Sci Alliance (2020) 3:e202000640. doi: 10.26508/LSA.202000640

123. Pawlowski A, Jansson M, Sköld M, Rottenberg ME, Källenius G. Tuberculosis and HIV co-infection. PloS Pathog (2012) 8:e1002464. doi: 10.1371/journal.ppat.1002464 
124. Huante MB, Nusbaum RJ, Endsley JJ. "Co-Infection with TB and HIV: Converging Epidemics, Clinical Challenges, and Microbial Synergy," in Tuberculosis Host-Pathogen Interactions, eds. J. D. Cirillo, Y. Kong. (Cham: Springer International Publishing), p. 123-53. doi: 10.1007/978-3030-25381-3_7

125. Orme IM, Basaraba RJ. The formation of the granuloma in tuberculosis infection. Semin Immunol (2014) 26:601-9. doi: 10.1016/j.smim.2014.09.009

126. Smith CM, Proulx MK, Olive AJ, Laddy D, Mishra BB, Moss C, et al. Tuberculosis Susceptibility and Vaccine Protection Are Independently Controlled by Host Genotype. (2016) 7:e01516-16. doi: 10.1128/mBio.01516-16

127. Heuts F, Gavier-Widén D, Carow B, Juarez J, Wigzell H, Rottenberg ME. CD4+ cell-dependent granuloma formation in humanized mice infected with mycobacteria. Proc Natl Acad Sci USA (2013) 110:6482-7. doi: 10.1073/ pnas. 1219985110

128. Arrey F, Löwe D, Kuhlmann S, Kaiser P, Moura-Alves P, Krishnamoorthy G, et al. Humanized Mouse Model Mimicking Pathology of Human Tuberculosis for in vivo Evaluation of Drug Regimens. Front Immunol (2019) 10:89-12. doi: 10.3389/fimmu.2019.00089

129. Calderon VE, Valbuena G, Goez Y, Judy BM, Huante MB, Sutjita P, et al. A Humanized Mouse Model of Tuberculosis. PloS One (2013) 8:e63331. doi: 10.1371/journal.pone.0063331

130. Nusbaum RJ, Calderon VE, Huante MB, Sutjita P, Vijayakumar S, Lancaster KL, et al. Pulmonary Tuberculosis in Humanized Mice Infected with HIV-1. Sci Rep (2016) 6:21522-11. doi: 10.1038/srep21522

131. Huante MB, Saito TB, Nusbaum RJ, Naqvi KF, Chauhan S, Hunter RL, et al. Small Animal Model of Post-chemotherapy Tuberculosis Relapse in the Setting of HIV Co-infection. Front Cell Infect Microbiol (2020) 10:150:150. doi: $10.3389 /$ fcimb.2020.00150

132. Greenblatt MB, Vbranac V, Tivey T, Tsang K, Tager AM, Aliprantis AO. Graft versus Host Disease in the Bone Marrow, Liver and Thymus Humanized Mouse Model. PloS One (2012) 7:e44664. doi: 10.1371/ journal.pone.0044664

133. Lockridge JL, Zhou Y, Becker YA, Ma S, Kenney SC, Hematti P, et al. Mice engrafted with human fetal thymic tissue and hematopoietic stem cells develop pathology resembling chronic graft-versus-host disease. Biol Blood Marrow Transplant (2013) 19:1310-22. doi: 10.1016/j.bbmt.2013.06.007

134. Lavender KJ, Pang WW, Messer RJ, Duley AK, Race B, Phillips K, et al. BLThumanized C57BL/6 Rag2-/- $\gamma \mathrm{c}-/$-CD47-/- mice are resistant to GVHD and develop B- and T-cell immunity to HIV infection. Blood (2013) 122:4013-20. doi: 10.1182/blood-2013-06-506949

135. Lavender KJ, Pace C, Sutter K, Messer RJ, Pouncey DL, Cummins NW, et al. An advanced BLT-humanized mouse model for extended HIV-1 cure studies. AIDS (2018) 32:1-10. doi: 10.1097/QAD.0000000000001674

136. Villaudy J, Schotte R, Legrand N, Spits H. Critical assessment of human antibody generation in humanized mouse models. J Immunol Methods (2014) 410:18-27. doi: 10.1016/j.jim.2014.06.010

137. McCune JM, Weissman IL. The Ban on US Government Funding Research Using Human Fetal Tissues: How Does This Fit with the NIH Mission to Advance Medical Science for the Benefit of the Citizenry? Stem Cell Rep (2019) 13:777-86. doi: 10.1016/j.stemcr.2019.10.003

138. McIntosh BE, Brown ME. No irradiation required: The future of humanized immune system modeling in murine hosts. Chimerism (2015) 6:40-5. doi: 10.1080/19381956.2016.1162360

139. Cosgun KN, Rahmig S, Mende N, Reinke S, Hauber I, Schäfer C, et al. Kit regulates HSC engraftment across the human-mouse species barrier. Cell Stem Cell (2014) 15:227-38. doi: 10.1016/j.stem.2014.06.001

140. Shultz LD, Saito Y, Najima Y, Tanaka S, Ochi T, Tomizawa M, et al. Generation of functional human T-cell subsets with HLA-restricted immune responses in HLA class I expressing NOD/SCID/IL2rynull humanized mice. Proc Natl Acad Sci USA (2010) 107:13022-7. doi: 10.1073/pnas.1000475107

141. Patton J, Vuyyuru R, Siglin A, Root M, Manser T. Evaluation of the efficiency of human immune system reconstitution in NSG mice and NSG mice containing a human HLA.A2 transgene using hematopoietic stem cells purified from different sources. J Immunol Methods (2015) 422:13-21. doi: 10.1016/j.jim.2015.02.007

142. Suzuki M, Takahashi T, Katano I, Ito R, Ito M, Harigae H, et al. Induction of human humoral immune responses in a novel HLA-DR-expressing transgenic NOD/Shi-scid/ $\gamma$ c null mouse. Int Immunol (2012) 24:243-52. doi: 10.1093/intimm/dxs045

143. Covassin L, Laning J, Abdi R, Langevin DL, Phillips NE, Shultz LD, et al. Human peripheral blood CD4 T cell-engrafted non-obese diabetic-scid IL2ry null H2-Ab1 tm1Gru Tg (human leucocyte antigen D-related 4) mice: A mouse model of human allogeneic graft-versus-host disease. Clin Exp Immunol (2011) 166:269-80. doi: 10.1111/j.1365-2249.2011.04462.x

144. Agarwal Y, Beatty C, Biradar S, Castronova I, Ho S, Melody K, et al. Moving beyond the mousetrap: Current and emerging humanized mouse and rat models for investigating prevention and cure strategies against HIV infection and associated pathologies. Retrovirology (2020) 17:1-11. doi: 10.1186/ s12977-020-00515-3

145. Legrand N, Huntington ND, Nagasawa M, Bakker AQ, Schotte R, StrickMarchand $\mathrm{H}$, et al. Functional CD47/signal regulatory protein alpha (SIRP $\alpha$ ) interaction is required for optimal human T- and natural killer- (NK) cell homeostasis in vivo. Proc Natl Acad Sci USA (2011) 108:13224-9. doi: 10.1073/pnas.1101398108

146. Allam A, Peachman KK, Aguilera-Olvera R, Casares S, Rao M. Isolation of human lymphocytes with high yield and viability from the gastrointestinal and female reproductive tract of a humanized DRAG mouse. J Immunol Methods (2018) 454:40-7. doi: 10.1016/j.jim.2017.12.004

147. Mendoza M, Ballesteros A, Qiu Q, Pow Sang L, Shashikumar S, Casares S, et al. Generation and testing anti-influenza human monoclonal antibodies in a new humanized mouse model (DRAGA: HLA-A2. HLA-DR4. Rag1 KO. IL-2R $\gamma$ c KO. NOD). Hum Vaccines Immunother (2018) 14:345-60. doi: 10.1080/21645515.2017.1403703

148. Mendoza M, Gunasekera D, Pratt KP, Qiu Q, Casares S, Brumeanu TD. The humanized DRAGA mouse (HLA-A2. HLA-DR4. RAG1 KO. IL-2R g c KO. NOD) establishes inducible and transmissible models for influenza type A infections. Hum Vaccines Immunother (2020) 16:2222-37. doi: 10.1080/ 21645515.2020 .1713605

149. Yi G, Xu X, Abraham S, Petersen S, Guo H, Ortega N, et al. Manjunath N. A DNA Vaccine Protects Human Immune Cells against Zika Virus Infection in Humanized Mice. EBioMedicine (2017) 25:87-94. doi: 10.1016/ j.ebiom.2017.10.006

150. Gille C, Orlikowsky TW, Spring B, Hartwig UF, Wilhelm A, Wirth A, et al. Monocytes derived from humanized neonatal NOD/SCID/IL2R $\gamma$ null mice are phenotypically immature and exhibit functional impairments. Hum Immunol (2012) 73:346-54. doi: 10.1016/j.humimm.2012.01.006

151. Li Y, Chen Q, Zheng D, Yin L, Chionh YH, Wong LH, et al. Induction of Functional Human Macrophages from Bone Marrow Promonocytes by MCSF in Humanized Mice. J Immunol (2013) 191:3192-9. doi: 10.4049/ jimmunol.1300742

152. Audigé A, Rochat MA, Li D, Ivic S, Fahrny A, Muller CKS, et al. Long-term leukocyte reconstitution in NSG mice transplanted with human cord blood hematopoietic stem and progenitor cells. BMC Immunol (2017) 18:28. doi: $10.1186 /$ s12865-017-0209-9

Conflict of Interest: The authors declare that the research was conducted in the absence of any commercial or financial relationships that could be construed as a potential conflict of interest.

Copyright $\odot 2021$ Gillgrass, Wessels, Yang and Kaushic. This is an open-access article distributed under the terms of the Creative Commons Attribution License (CC BY). The use, distribution or reproduction in other forums is permitted, provided the original author(s) and the copyright owner(s) are credited and that the original publication in this journal is cited, in accordance with accepted academic practice. No use, distribution or reproduction is permitted which does not comply with these terms. 